\title{
RADAR BACKSCATTER AND OPTICAL TEXTURAL INDICES FUSION FOR PINE PLANTATION STRUCTURE MAPPING
}

\author{
A. Shamsoddini \\ School of Surveying and Spatial Information Systems, university of New South Wales, Sydney, Australia- \\ a.shamsoddini@student.unsw.edu.au
}

\section{Commission VII, WG6}

\author{
KEYWORDS: SAR, SPOT, Fusion, Forestry, Texture, Estimation
}

\begin{abstract}
One of the most important concerns of remote sensing research has been the quantification of forest structure variables. This issue has been investigated using different remotely sensed data including optical, radar and lidar data. Moreover, the utility of multisensor data has been examined for this task. Radar images are being considered as one of the available tools for forest studies; however, some constrains of this data such as speckle noise and the high sensitivity of this data to topography prevent it from being widely utilized for forest structure mapping. A possible solution is to integrate radar data with optical data to improve the accuracy of the biophysical parameter estimations; however, the results of the common fusion method does not show significant improvement if the efficacy of one of the datasets is much lower than the other one. In this study multi-date ALOS/PALSAR data with HH and HV polarizations were used along with SPOT-5 textural indices derived from the grey level co-occurrence matrix (GLCM), and the subtract and sum histogram (SADH), calculated in different orientations and window sizes for retrieval of a Pinus radiata plantation at plot-level in NSW, Australia. In order to overcome the deficiency of the common fusion method, a new fusion method called ratio fusion is examined for fusion of radar and optical data. The results showed that the estimation of biophysical parameters including mean height, mean DBH, stand volume, basal area and stocking using SPOT-5 textural indices was more accurate than that derived using the backscatter data derived from multi-date ALOS/PALSAR images. Also, the accuracy of estimation of these forest structure parameters increases when the ratio of the SPOT-5 textural indices to the radar backscatter is used for this task.
\end{abstract}

\section{INTRODUCTION}

Parameterization of forest structure is a recent important area of study by remote sensing researchers over the last few decades. This information is required as input for global change models and sustainable forest management. Different types of remotely sensed data including: optical (Kayitakire et al., 2006; Wolter et.al, 2009); radar (Townsend, 2002; Neumann et al., 2010); and lidar data (Drake et al., 2002; Sherrill et al., 2008); were investigated for mapping forest structure parameters. Also, the synergy these datasets has been examined and proved to increase the feasibility of each dataset for forest structure mapping (Slatton et al., 2001; Nelson et al., 2007; Erdody and Moskal, 2010; Tonolli et al., 2011). Although optical sensors are not able to acquire information of understorey, especially for dense canopies (Wulder, 1998), they provide a wide range of spectral and spatial resolutions which are useful for biophysical parameter estimation. Hence, it is possible to utilize different spectral attributes such as individual bands, band ratios, and vegetation indices as well as different textural attributes derived from optical data for this purpose; however, the strength of textural attributes for retrieval of biophysical parameters compared to the space-borne spectral information has been demonstrated by several studies (Ryherd and Woodcock, 1996; Wulder at al., 1998; Hyyppa et al., 2000).

Radar images which are acquired in longer wavelengths such as $\mathrm{L}$ band, contain some information about the lower parts of the canopy such as the trunk; however, speckle noise, effects of slope and environmental conditions such as soil wetness (Wang et al., 2000) lead to the reduction in the capability of the radar data for retrieval of the biophysical parameters with acceptable accuracy. The lower efficiency of radar data compared to other remotely sensed data for mapping forest structure characteristics has been demonstrated by Hyyppa et al. (2000). Although, interferometric SAR (InSAR) and coherence images can provide vertical structural information over forests, they do not perform efficiently for estimating forest variables (Treuhaft et al., 2004).According to these considerations, the fusion of radar and optical data may overcome the deficiencies of individual datasets and in combination increase their ability for estimating biophysical parameters, including mean height, mean diameter at breast height (DBH), basal area, stand volume and stocking.

There are three levels of data fusion including primary data (or pixel) level, attribute (or feature) level and decision level (Pohl and Van Genderen, 1998). The lowest level of the fusion of the two datasets is the extraction of the attributes from the average or ratio of the two images. This method can be applied when the characteristics of two datasets are the same, such as two optical images with the same spatial resolution, and if appropriate, following resampling (Nichol and Sarker, 2011), or two SAR images (Ranson and Sun, 1994; Dobson et al., 1995). The common method for fusion of the remotely sensed data for estimating biophysical parameters is feature level fusion that extracts attributes from different datasets and combines them using multiple-linear regression methods (Hyde et al., 2006; Erdody and Moskal, 2010; Banskota et al., 2011; Tonolli et al., 2011). According to these studies, although this method can lead to improved results over those derived from individual datasets, the multicollinearity effect prevents the use of more predictors to increase the accuracy. Moreover, stepwise 
multiple-linear regression would normally select the significantly correlated attributes derived from the dataset with higher efficacy. Consequently, when the performance of attributes derived from one remotely sensed dataset is much better than that derived from another, the fusion does not lead to significant improvements since the final model is usually formed using the attributes of the one dataset with high efficacy and attributes of the other datasets are ineffective. In order to overcome these deficiencies, the ratios of the attributes extracted from two different remotely sensed datasets were used in this study using multiple-linear regression. In fact, this process leads to the generation of pseudo-attributes whose values are determined not only by one set of remotely sensed data, but the other as well. It is believed that the performance of the pseudo-attributes is more efficient than real attributes when the multiple-linear regression is applied. Examination of this hypothesis is the aim of this paper. The main novelties of this study are as follows:

- The comparison of SPOT-5 and multi-date dual polarized ALOS/PALSAR data as two optical and radar datasets with similar spatial resolutions for estimating biophysical parameters at plot-level.

- Examination of the feasibility of ALOS/PALSAR backscatter derivatives and SPOT-5 textural attributes in synergistic mode using a new fusion strategy called ratio fusion, for forest structure mapping at plot-level.

In the next sections, the study area and remotely sensed data used for this study are explained. Then, the methodology and results are given and finally the results are discussed and the paper is concluded by the last section.

\section{STUDY AREA AND DATA}

A 5000 ha commercial Pinus radiata plantation was surveyed in 2008 near Batlow, NSW, Australia. After accurately positioning trees and plot centres using a laser theodolite (Leica T1100 total station) and a differential global positioning system (dGPS), two parameters including DBH and height were measured for 978 trees within 63 variable radius-size plots ranging from $7 \mathrm{~m}$ to $20 \mathrm{~m}$. The stem volume of each tree also was calculated using an in-house equation (Dr Huiquan Bi, personal communication, 2011). The plot collection aimed to cover three different strata including: slope (less than 10 degrees, more than 10 and less than 20 degrees and more than 30 degrees); thinning condition (unthinned, first thinning and second thinning); and tree age (less than 20 years and more than 20 years). For each plot which contains at least 15 stems, five forest structure parameters including mean height, mean $\mathrm{DBH}$, stocking, basal area and stand volume were calculated using the field collected data and calculated stem volume. The statistical information of 61 plots used for this study is shown in table 1 .

\begin{tabular}{|c|cccc|}
\hline $\begin{array}{c}\text { Biophysical } \\
\text { parameter }\end{array}$ & Min & Max & Mean & $\begin{array}{c}\text { Standard } \\
\text { deviation }\end{array}$ \\
\hline $\begin{array}{c}\text { Height }(\mathrm{m}) \\
\text { Mean DBH }(\mathrm{cm})\end{array}$ & 12.2 & 33.6 & 24.0 & 5.7 \\
$\begin{array}{c}\text { Stand volume } \\
\text { (m3/ha) }\end{array}$ & 106.5 & 760.3 & 296.0 & 128.7 \\
$\begin{array}{c}\text { Basal area } \\
\text { (m2/ha) }\end{array}$ & 18.0 & 65.4 & 33.7 & 10.8 \\
Stocking & 121 & 1429 & 595 & 371.1 \\
\hline
\end{tabular}

Table 1 . The summary of the statistical information for the 61 plots used in this study

Multispectral SPOT-5 data including green, red, near infrared (NIR) and short wavelength infrared (SWIR) bands which were acquired on 5 April 2008 were used for this study. The orthorectified data was provided with spatial resolution of $10 \mathrm{~m}$ (SWIR was resampled to $10 \mathrm{~m}$ ). Moreover, two dual-polarized ALOS/ PALSAR images (HH and HV) acquired on 9 August 2008 and 24 September 2008 were provided by Japan Aerospace Exploration Agency (JAXA). The synthetic aperture radar (SAR) images were 2-look magnitude data which were orthorectified using the $90 \mathrm{~m}$ SRTM digital elevation model.

\section{METHODOLOGY}

According to figure 1, the methodology used in this study can be divided into four parts including data pre-processing, attribute extraction, modelling, and fusion.

\subsection{Data Pre-processing}

The orthorectified Spot-5 multispectral image was corrected geometrically to an orthorectified WorldView-2 image (2-m spatial resolution) using 50 ground control points collected over the image with the registration accuracy of less than half metre.

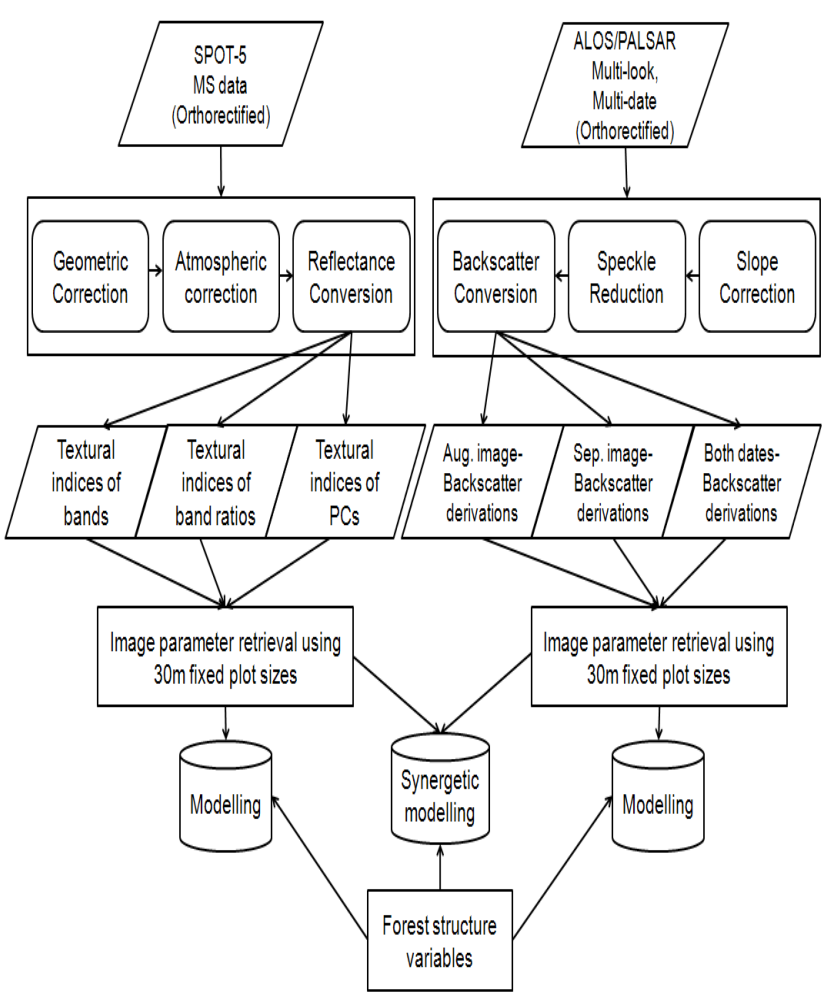

Figure 1. The methodology used in this study

Also, the atmospheric correction of this data was undertaken using dark object subtract method (DOS3) and digital numbers were converted to reflectance values. There was no need for topographic correction as the examination of the relationship between the cosine of the incident angle, cos (i), which is the incident angle between the sun and a horizontal surface was calculated according to Riano et al. (2003), and the radiance of each band does not show significant correlation after removal of path radiance.

SAR data are significantly affected by slope. In order to reduce this effect the orthorectification and slope correction was done by data provider (JAXA Company) using the method developed by Shimada (2010). As mentioned one of the main problems of 
the SAR data is speckle noise. The UNSW adaptive filter (UAF) developed by Shamsoddini and Trinder (2012) was used to suppress the speckle noise over the SAR data applied. The main advantage of this filter is the suppression of the speckle noise and preservation of the edges and texture on the SAR image (Shamsoddini and Trinder, 2010). Then the processed data was registered to the SPOT-5 image using 40 GCPs with an accuracy of less than half pixel. The conversion of the magnitude values to backscatter coefficient was done using the standard equation provided by JAXA as follows:

$$
\sigma^{0}=10 \log _{10}\left(D N^{2}\right)+C F
$$

where $\sigma^{0}=$ radar backscatter coefficient $\mathrm{DN}=$ Magnitude value

$$
\mathrm{CF}=-83
$$

\subsection{Attribute Extraction}

The most relevant Grey Level Co-occurrence Matrix (GLCM) textural attributes according to the literature (Baraldi and Parmiggiani, 1995; Carr and de Miranda, 1998; Solberg, 1999; Pesaresi, 2000; Rao et al., 2002; Lu, 2005; Tuominen and Pekkarinen, 2005; Kayitakire et al., 2006), including Mean (ME), Variance (VAR), Standard Deviation (ST), Contrast (CON), Angular Second Moment (ASM), Entropy (ENT), Homogeneity (HOM), Energy (EN), Correlation (CO), Dissimilarity (DISS), and Maximum Probability (MP) have been calculated by MATLAB 7.9.0, for different spectral derivatives of SPOT-5 multispectral data including individual bands, band ratios and principle components (PCs), for four window sizes including $3 \times 3$ to $9 \times 9$, along with four different window orientations comprising of $0^{\circ}, 45^{\circ}, 90^{\circ}$ and $135^{\circ}$. In addition to GLCM, sum and difference histogram (SADH) attributes proposed by Unser (1986) were calculated for the same window sizes. The SADH attributes include Mean (ME), Mean deviation (MD), Mean Euclidean distance (MED), Variance (VAR), Coefficient of variation (CV), Skewness (SK), Kurtosis (KU), Energy (EN), Entropy (ENT). Table 2 shows the different backscatter derivatives from two-date dual-polarized SAR data used in this study. The same textural attributes mentioned above were calculated for the backscatter derivatives in table 2. All of the calculated attributes were extracted within 30-m radius plots.

\begin{tabular}{|c|c|}
\hline Code & Backscatter derivative \\
\hline 1 & HH-Aug \\
2 & HV-Aug \\
3 & HH-Sep \\
4 & HV-Sep \\
5 & Ratio of HH and HV-Aug \\
6 & Ratio of HH and HV-Sep \\
7 & Difference of HH and HV-Aug \\
8 & Difference of HH and HV-Sep \\
9 & Normalized difference of HH and HV-Aug \\
10 & Normalized difference of HH and HV-Sep \\
11 & Difference of Sep and Aug-HH \\
12 & Difference of Sep and Aug-HV \\
13 & Ratio of Sep and Aug-HH \\
14 & Ratio of Sep and Aug-HV \\
\hline
\end{tabular} Table 2. Backscatter derivatives derived from SAR data used in this
study

\subsection{Modelling}

Among the different modelling methods suggested in the literature, a stepwise multiple-linear regression, which is the common method for estimating forest variables using remotely sensed data (Kasischke et al., 1995; Næsset, 2002; Hudak et al., 2002; Sarker and Nichol, 2011), was applied to examine the prediction strength of each dataset individually and in fused mode. According to Harris (1985), in order to avoid over-fitting and multicollinearity problems the number of predictors in each model was limited to at most 10 , calculated based on the number of available plots which is 61 . Moreover, according to Belsley (1991), the models with the variance inflation factor $(\mathrm{VIF}=1 / 1-\mathrm{R} 2)$ values higher than 10 , tolerance (Tol=1-R2) values lower than 0.1 , eigenvalue $(\mathrm{EV})$ close to zero, condition index (CI) values higher than 30 and finally p-level values higher than 0.05 , for each model or predictor, were excluded. Coefficient of determination $\left(\mathrm{R}^{2}\right)$ and standard error of estimation (SEE) were calculated to compare the capability of each dataset when used individually and together, for estimating biophysical parameters.

\subsection{Fusion}

The ratio of the attributes extracted from two different remotely sensed datasets were used in this study to overcome the limitations of the averaging method and also common fusion method using multiple-linear regression. The concept behind ratio fusion method is that the ratio of the attributes derived from two different datasets can reduce the saturation effect which occurs for individual data. The main condition for this approach to fusion is the efficacy of the two datasets. It means that if the performance of a dataset is very poor but better than random data for predicting a variable, it will still provide some information to the fusion process.

\section{RESULTS AND DISCUSSION}

\subsection{Multi-date SAR Images}

After calculating the GLCM and SADH textural attributes for backscatter derivatives of SAR images, no relationship was found between these attributes and biophysical parameters. It seems there are different issues affecting the results of textural analysis. These issues are (i) incomplete removal of speckle noise, even after applying speckle noise suppression; (ii) incomplete slope correction; (iii) the effect of rainfall which occurred a day before the acquisition of both SAR images as it can affect the soil moisture content and consequently there could be similar backscatter responses from different parts of the plantation (Wang et al., 2000). As figure 2 shows the estimation results which were acquired from the backscatter derivatives of both SAR images are better than those derived from textural indices.

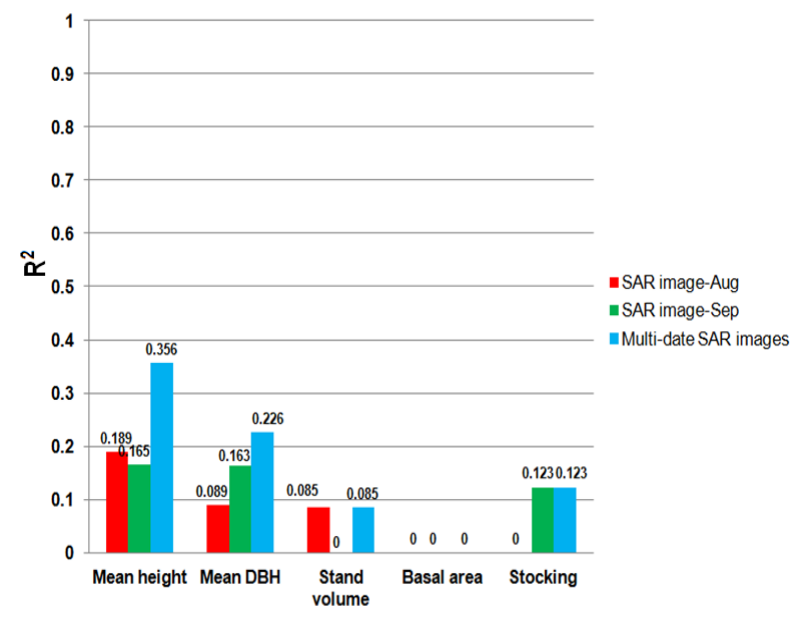

Figure 2 . The $\mathrm{R}^{2}$ results of SAR images individually and together 
According to figure 2, backscatter derivations of two-dates SAR data can provide better estimations of mean height and mean DBH. Mean height was estimated better than other parameters with $\mathrm{R}^{2}$ of 0.36 and SEE of $4.7 \mathrm{~m}$, while the basal area was not modelled with SAR data if the multicollinearity effect is considered. Also, mean DBH is estimated with $\mathrm{R}^{2}$ of 0.23 and SEE of $8.66 \mathrm{~cm}$ that is relatively better than stand volume and stocking estimations with $\mathrm{R}^{2}$ of 0.09 and 0.12 , and SEEs of 124 $\mathrm{m}^{3} /$ ha and 351 tree/ha, respectively.

\subsection{SPOT-5 Textural Attributes}

As mentioned earlier GLCM and SADH textural attributes were calculated using three types of spectral derivatives including individual bands, band ratios and PCs. Figure 3 shows the results of $R^{2}$ derived for the prediction models based on the textural attributes from each type of spectral derivations. As figure 3 shows that the performance of the SPOT-5 textural attributes are significantly better than those derived from SAR images for estimating biophysical parameters, as the optical data is not affected by the soil moisture as is the radar data. Also, the effect of the terrain slope on the SPOT-5 data is not significant. Moreover, although the spatial resolution of these two remotely sensed datasets is similar, the higher spectral resolution of SPOT-5 data compared to that of the ALOS/PALSAR is another issue leading to its more efficient performance than the radar data. While the best estimations of mean height and stocking were derived using textural attributes of all PCs with $\mathrm{R}^{2}$ of 0.82 and 0.77 and SEEs of $2.7 \mathrm{~m}$ and 187 tree/ha respectively, the best results obtained from textural attributes of all band ratios were for mean DBH and basal area with $\mathrm{R}^{2}$ of 0.78 and 0.70 and SEEs of $4.9 \mathrm{~cm}$ and $6.5 \mathrm{~m}^{2} / \mathrm{ha}$, respectively. Finally, the best prediction from textural attributes of all bands was for stand volume with $\mathrm{R}^{2}$ of 0.61 and SEE of $86.1 \mathrm{~m}^{3} / \mathrm{ha}$.

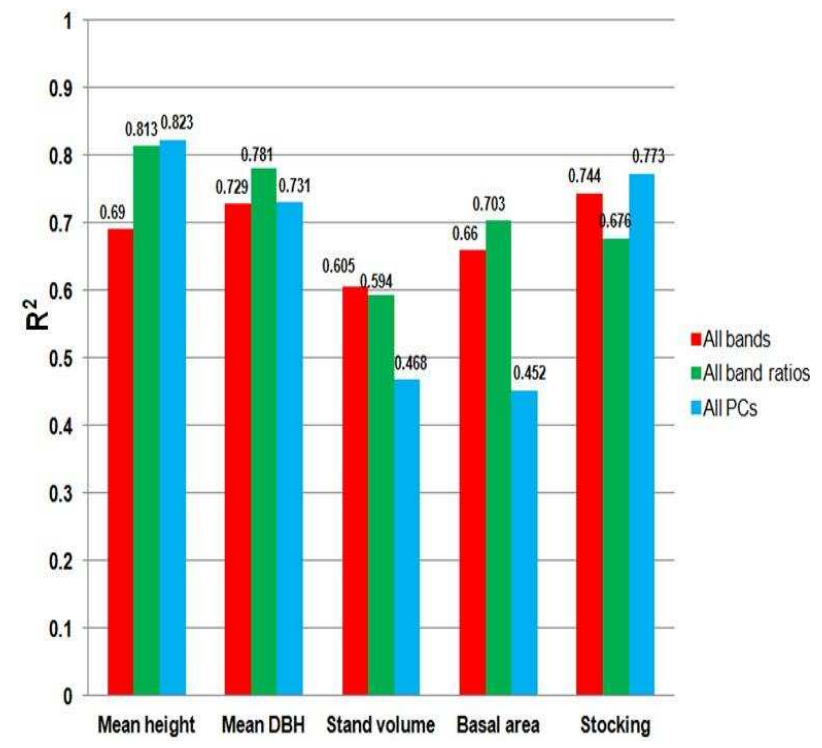

Figure 3. The $\mathrm{R}^{2}$ results of textural attributes derived from SPOT-5 spectral derivations

\subsection{Fusion of SAR and Optical Data}

The common fusion and ratio fusion methods described in section 1 of this study where applied for estimating biophysical parameters. While the common method of fusion did not improve the estimation results of biophysical parameters derived using only SPOT-5 data, except for mean height and mean $\mathrm{DBH}$, the ratio fusion method significantly improved the results of the forest structure mapping as shown in bold text in table 3. While the best results for basal area and stocking were derived using ratio fusion of backscatter derivatives of radar data and textural attributes of SPOT-5 individual bands, the integration of radar backscatter derivatives and textural attributes of SPOT-5 band ratios gives the best estimations of stand volume and mean DBH. Moreover, the combination of radar backscatter derivatives and textural attributes of SPOT-5 PCs provides the best estimation of mean height.

\begin{tabular}{|c|ccc|}
\hline Biophysical Parameter & Fusion strategy & $\mathrm{R}^{2}$ & SEE \\
\hline \multirow{2}{*}{ Mean height $(\mathrm{m})$} & Common & 0.841 & 2.50 \\
& Ratio & $\mathbf{0 . 8 8 4}$ & $\mathbf{2 . 1 4}$ \\
Mean DBH $(\mathrm{cm})$ & Common & 0.799 & 4.76 \\
& Ratio & $\mathbf{0 . 8 6 9}$ & $\mathbf{3 . 8 4}$ \\
Stand Volume $\left(\mathrm{m}^{3} / \mathrm{ha}\right)$ & Common & 0.605 & 86.07 \\
& Ratio & $\mathbf{0 . 8 0 0}$ & $\mathbf{6 2 . 9 6}$ \\
Basal area $\left(\mathrm{m}^{2} / \mathrm{ha}\right)$ & Common & 0.660 & 6.77 \\
& Ratio & $\mathbf{0 . 7 6 6}$ & $\mathbf{5 . 7 2}$ \\
Stocking (tree/ha) & Common & 0.773 & 187 \\
& Ratio & $\mathbf{0 . 8 8 5}$ & $\mathbf{1 3 8}$ \\
\hline
\end{tabular}

Table 3. The best results derived from fusion

\subsection{Validation and Strata Effect}

Validation of the selected models derived from ratio fusion was evaluated using the leave-one-out cross validation method (Efron and Tibshirani, 1993), as it is required to calculate the generalization error of each model. This method has been widely used in the remotely sensing literature for forest applications (Anderson et al., 2005; Kayitakire et al., 2006; Meng et al., 2007). Table 4 shows the prediction errors of biophysical parameters using the models derived from ratio fusion of SPOT-5 textural attributes and SAR backscatter derivatives. Table 4 shows that the ratio fusion of SPOT-5 and ALOS/PALSAR data is able to decrease the error of estimation for mean height, mean DBH to lower than $15 \%$ to $20 \%$ which is the acceptable sampling inventory error in forest inventory (Holmgren and Thuresson, 1998).

\begin{tabular}{|c|ccc|}
\hline Biophysical Parameter & $\mathrm{R}^{2}$ & $\begin{array}{c}\text { Prediction Error } \\
\text { (SEE) }\end{array}$ & $\begin{array}{c}\text { Error of } \\
\text { Estimation } \\
(\%)\end{array}$ \\
\hline Mean height $(\mathrm{m})$ & 0.825 & 2.6 & 10.8 \\
Mean DBH $(\mathrm{cm})$ & 0.804 & 4.7 & 15.6 \\
Stand Volume $\left(\mathrm{m}^{3} / \mathrm{ha}\right)$ & 0.639 & 84.8 & 28.6 \\
Basal area $\left(\mathrm{m}^{2} / \mathrm{ha}\right)$ & 0.659 & 6.9 & 20.5 \\
Stocking (tree/ha) & 0.823 & 173 & 29.1 \\
\hline
\end{tabular}

After prediction of biophysical parameters using the selected models, the effect of different strata including thinning condition, age of tree and slope condition on the results of the predictions were examined. For this purpose, an independent sample t-test was applied on the residuals derived from the predicted and measured values of each biophysical parameter, to indicate the effect of the different classes of each stratum. The residuals were considered in two modes including absolute and actual values (that is, considering the sign of the residuals). The independent sample t-test on absolute values of residuals indicated the effect of different classes of each stratum on the accuracy of the prediction, while applying this test on actual values of residuals reveals the effect of the classes on underestimation or overestimation of the parameters. Two hypothesis including $\mathrm{H}_{0}$ for the equality and $\mathrm{H}_{1}$ for inequality of the mean values of two classes were tested at $\alpha$ level of 0.05 . If the significance level of the t-test was less than 0.05, the hypothesis of $\mathrm{H}_{1}$ was accepted; otherwise $\mathrm{H}_{0}$ was accepted 
which means there is no difference between the residuals of two classes.

The results of the t-test on the absolute values of the residuals derived from the predicted and measured values showed no significant difference between the different classes of the strata and absolute values of the residuals at p-level of 0.05 . This means that age, thinning and slope classes do not significantly affect the results of the prediction.

According to the t-test on actual values of residuals, two tree age classes, less than 20 years and more than 20 years showed no significant differences for mean height, mean DBH and stocking, while the difference between the actual residuals of these two age classes are significant for basal area and stand volume. While the basal area and stand volume values were overestimated for the plots less than 20 year, the predicted values were underestimated for plots more than 20 years. The results of the t-test on actual residuals derived for the three classes of thinning condition shows that there is no significant difference among thinning classes for stand volume and basal area predictions. The difference between unthinned and first thinning is not significant for mean height, mean DBH and stocking predictions, while the difference between these two thinning classes and the second thinning class are significant for actual residuals of these biophysical parameters, except when the prediction of mean height is considered, for the difference between residuals of unthinned and second thinning classes. Examining the actual residuals of the thinning classes whose actual residual differences were significant indicated:

- While the stocking predictions of unthinned and first thinning classes were underestimated, the average of actual residuals of the predictions at second thinning class shows overestimation.

- Thinning classes have inverse effect on mean DBH and mean height predictions as the average value of actual residuals of plots for the second thinning class shows underestimation compared to the unthinned and first thinning classes.

Finally, the t-test analysis on the actual residuals of the predictions among different slope classes showed that there is a significance difference for basal area predictions between slope classes of less than 10 degree where the predictions were on average overestimated and higher than 20 degree where the predictions were on average underestimated. The classes of this stratum did not show significance effect on the rest of biophysical parameters.

\section{CONCLUSION}

The performance of SPOT- 5 multispectral image and multi-date dual-polarized ALOS/PALSAR with similar spatial resolutions were compared in this paper for estimating biophysical parameters of a Pinus radiata plantation. The results showed the performance of the textural attributes of SPOT-5 data was significantly better than those of ALOS/PALSAR data. Moreover, a new method of fusion called ratio fusion was examined for integrating the optical textural attributes and radar backscatter attributes. The results showed significant improvement in the accuracy of the biophysical parameter estimations compared to that derived for SPOT-5 and ALOS/PALSAR data. It was proved that the common fusion method failed to increase the accuracy of the biophysical parameter estimations due to low efficacy of SAR backscatter attributes, whereas ratio fusion method is able to increase this accuracy due to the injection of the information of SAR backscatter attributes into the SPOT-5 textural attributes. Leaveone-out cross validation results indicated that mean height, mean DBH and basal area can be predicted with an error lower than $20 \%$ which is better than acceptable sampling error of forest field inventory. Examining the effect of the strata on the prediction values using an independent sample t-test showed that the accuracy of the predictions are not affected by these strata, however, they can cause underestimation or overestimation of the biophysical parameter predictions. Finally, capability of the ratio fusion method for integrating different remotely sensed data for forest structure mapping should be investigated further in the future studies.

\section{Acknowledgement}

The author would like to thank Prof. John Trinder and Dr. Russell Turner for their great supports. Lidar-derived and field data utilized in this study was kindly supplied by Dr. Christine Stone from the New South Wales Department of Industry and Investment (IINSW) and Forests NSW (FNSW), with partial sponsorship from the Forest and Wood Products Australia (FWPA). Also, I like to appreciate JAXA Company for providing ALOS/PALSAR data.

\section{Reference}

Andersen, H.-E., McGaughey, R. J. \& Reutebuch, S. E., 2005. Estimating forest canopy fuel parameters using LIDAR data. Remote Sensing of Environment, 94, pp. 441-449.

Baraldi, A., \& Parmiggiani, F., 1995. An investigation of the textural characteristics associated with gray level cooccurrence matrix statistical parameters. IEEE Transactions on Geoscience and Remote Sensing, 33, pp. 293-304.

Belsley, D. A., 1991. Conditioning Diagnostics, New York, Wiley.

Banskota, A., Wynne, R., Johnson, P., \& Emessiene, B., 2011. Synergistic use of very high-frequency radar and discrete-return lidar for estimating biomass in temperate hardwood and mixed forests. Annals of Forest Science, 68, pp. 347-356.

Carr, J. R., \& De Miranda, F. P., 1998. The semivariogram in comparison to the co-occurrence matrix for classification of image texture. IEEE Transactions on Geoscience and Remote Sensing, 36, pp. 1945-1952.

Dobson, M. C., Ulaby, F. T., Pierce, L. E., Sharik, T. L., Bergen, K. M., Kellndorfer, J., Kendra, J. R., Li, E., Lin, Y. C., Nashashibi, A., Sarabandi, K., \& Siqueira, P., 1995. Estimation of forest biophysical characteristics in Northern Michigan with SIR-C/X-SAR. IEEE Transactions on Geoscience and Remote Sensing, 33, pp. 877-895.

Drake, J. B., Dubayah, R. O., Clark, D. B., Knox, R. G., Blair, J. B., Hofton, M. A., Chazdon, R. L., Weishampel, J. F. \& Prince, S., 2002. Estimation of tropical forest structural characteristics using large-footprint lidar. Remote Sensing of Environment, 79, pp. 305-319.

Efron, E. \& Tibshirani, R., 1993. An introduction to the bootstrap. Champman \& Hall, New York.

Erdody, T. L., \& Moskal, L. M., 2010. Fusion of LiDAR and imagery for estimating forest canopy fuels. Remote Sensing of Environment, 114, pp.725-737.

Harris, R.J., 1985. A primer of multivariate statistics (2nd Ed.). New York: Academic Press.

Holmgren, P., \& Thuresson, T., 1998. Satellite remote sensing for forestry planning. A review. Scandinavian Journal of Forest Research, 13, pp. 90 - 110.

Hudak, A. T., Lefsky, M. A., Cohen, W. B., \& Berterretche, M., 2002. Integration of lidar and Landsat ETM+ data for 
estimating and mapping forest canopy height. Remote Sensing of Environment, 82, pp. 397-416.

Hyde, P., Dubayah, R., Walker, W., Blair, J. B., Hofton, M., \& Hunsaker, C., 2006. Mapping forest structure for wildlife habitat analysis using multi-sensor (LiDAR, SAR/InSAR, ETM+, Quickbird) synergy. Remote Sensing of Environment, 102, pp. 63-73.

Hyyppa, J., Hyyppa, H., Inkinen, M., Engdahl, M., Linko, S., \& Zhu, Y.-H., 2000. Accuracy comparison of various remote sensing data sources in the retrieval of forest stand attributes. Forest Ecology and Management, 128, pp.109-120.

Kasischke, E. S., Christensen, N. L., JR., \& Bourgeau-Chavez, L. L., 1995. Correlating radar backscatter with components of biomass in loblolly pine forests. IEEE Transactions on Geoscience and Remote Sensing, 33, pp. 643-659.

Kayitakire, F., Hamel, C., \& Defourny, P., 2006. Retrieving forest structure variables based on image texture analysis and IKONOS-2 imagery. Remote Sensing of Environment, 102, pp.390-401.

Lu, D., 2005. Aboveground biomass estimation using Landsat TM data in the Brazilian Amazon. International Journal of Remote Sensing, 26, pp. 2509 - 2525.

Meng, Q., Cieszewski, C., Madden, M. \& Borders, B. 2007. K Nearest Neighbor method for forest inventory using remote sensing data. GIScience \& Remote Sensing, 44, 149-165.

Næsset,, E., 2002. Predicting forest stand characteristics with airborne scanning laser using a practical two-stage procedure and field data. Remote Sensing of Environment, 80, pp. 88-99.

Nelson, R. F., Hyde, P., Johnson, P., Emessiene, B., Imhoff, M. L., Campbell, R., \& Edwards, W., 2007. Investigating RaDARLiDAR synergy in a North Carolina pine forest. Remote Sensing of Environment, 110, pp. 98-108.

Neumann, M., Ferro-Famil, L., \& Reigber, A., 2010. Estimation of Forest Structure, Ground, and Canopy Layer Characteristics From Multibaseline Polarimetric Interferometric SAR Data. IEEE Transactions on Geoscience and Remote Sensing, 48, pp. 1086-1104.

Nichol, J. E. \& Sarker, M. L. R., 2011. Improved biomass estimation using the texture parameters of two high-resolution optical sensors. IEEE Transactions on Geoscience and Remote Sensing, 49, pp. pp. 930-948.

Pesaresi, M., 2000. Texture analysis for urban pattern recognition using fine-resolution panchromatic satellite imagery. Geographical and Environmental Modelling, 4, pp. 43 - 63.

Pohl, C. \& Van Genderen, J. L., 1998. Review article Multisensor image fusion in remote sensing: Concepts, methods and applications. International Journal of Remote Sensing, 19, pp. 823-854.

Rao, P. V. N., Sai, M. V. R. S., Sreenivas, K., Rao, M. V. K., Rao, B. R. M., Dwivedi, R. S. \& Venkataratnam, L., 2002. Textural analysis of IRS-1D panchromatic data for land cover classification. International Journal of Remote Sensing, 23, pp. $3327-3345$.

Riano, D., Chuvieco, E., Salas, J., \& Aguado, I., 2003. Assessment of different topographic corrections in Landsat-TM data for mapping vegetation types. IEEE Transactions on Geoscience and Remote Sensing, 41, pp. 1056-1061.

Ryherd, S. \& Woodcock, C. E., 1996. Combining spectral and texture data in the segmentation of remotely sensed images. Photogrammetric engineering and remote sensing 62, pp. 181194.

Ranson, K. J., \& Sun, G., 1994. Mapping biomass of a northern forest using multifrequency SAR data. IEEE Transactions on Geoscience and Remote Sensing, 32, pp. 388-396.

Sarker, L. R. \& Nichol, J. E., 2011. Improved forest biomass estimates using ALOS AVNIR-2 texture indices. Remote Sensing of Environment, 115, pp. 968-977.
Shamsoddini, A. \& Trinder, J. C., 2010. Image texture preservation in speckle noise suppression. In: ISPRS TC VII Symposium - 100 Years ISPRS, Vienna, Austria, Vol. XXXVIII, Part 7A, pp. 239-243.

Shamsoddini, A. \& Trinder, J. C., 2012. Edge-detection-based filter for SAR speckle noise reduction. International Journal of Remote Sensing, 33, pp.2296-2320.

Sherrill, K. R., Lefsky, M. A., Bradford, J. B., \& Ryan, M. G., 2008. Forest structure estimation and pattern exploration from discrete-return lidar in subalpine forests of the central Rockies. Canadian Journal of Forest Research, 38, pp.2081-2096.

Shimada, M. 2010. Ortho-Rectification and Slope Correction of SAR Data Using DEM and Its Accuracy Evaluation. Selected Topics in Applied Earth Observations and Remote Sensing, IEEE Journal of, 3, pp.657-671.

Slatton, K. C., Crawford, M. M., \& Evans, B. L., 2001. Fusing interferometric radar and laser altimeter data to estimate surface topography and vegetation heights. IEEE Transactions on Geoscience and Remote Sensing, 39, pp. 2470-2482.

Solberg, A. H. S., 1999. Contextual data fusion applied to forest map revision. IEEE Transactions on Geoscience and Remote Sensing, 37, pp. 1234-1243.

Tonolli, S., Dalponte, M., Neteler, M., Rodeghiero, M., Vescovo, L., \& Gianelle, D., 2011. Fusion of airborne LiDAR and satellite multispectral data for the estimation of timber volume in the Southern Alps. Remote Sensing of Environment, 115, pp. 2486-2498.

Townsend, P. A., 2002. Estimating forest structure in wetlands using multitemporal SAR. Remote Sensing of Environment, 79, pp. 288-304.

Treuhaft, R. N., Law, B. E. \& Asner, G. P., 2004. Forest attributes from radar interferometric structure and its fusion with optical remote sensing. BioScience, 54, pp. 561-571.

Tuominen, S., \& Pekkarinen, A., 2005. Performance of different spectral and textural aerial photograph features in multi-source forest inventory. Remote Sensing of Environment, 94, pp. 256268.

Unser, M., 1986. Sum and difference histograms for texture classification. IEEE Trans. Pattern Anal. Mach. Intell., PAMI8 (1), pp. 118-125.

Wang, Y., Kasischke, E. S., Bourgeau-Chavez, L. L., O'Neill, K. P., \& French, N. H. F., 2000. Assessing the influence of vegetation cover on soil-moisture signatures in firedisturbed boreal forests in interior Alaska: Modelled results. International Journal of Remote Sensing, 21, pp.69-708.

Wolter, P. T., Townsend, P. A. \& Sturtevant, B. R., 2009. Estimation of forest structural parameters using 5 and 10 meter SPOT-5 satellite data. Remote Sensing of Environment, 113, pp.2019-2036.

Wulder, M. 1998. Optical remote-sensing techniques for the assessment of forest inventory and biophysical parameters. Progress in Physical Geography, 22, pp. 449-476.

Wulder, M. A., Ledrew, E. F., Franklin, S. E. \& Lavigne, M. B., 1998. Aerial image texture information in the estimation of northern deciduous and mixed wood forest leaf area index (LAI). Remote Sensing of Environment, 64, pp. 64-76.

Wulder, M. A., \& Seemann, D., 2003. Forest inventory height update through the integration of lidar data with segmented Landsat imagery. Canadian Journal of Remote Sensing, 29, pp.536-543. 